\title{
Growth Hormone and Aging: Updated Review
}

\author{
Andrzej Bartke ${ }^{(i)}$ \\ Department of Internal Medicine, Southern Illinois University School of Medicine, Springfield, IL, USA
}

\begin{abstract}
Role of growth hormone $(\mathrm{GH})$ in mammalian aging is actively explored in clinical, epidemiological, and experimental studies. The age-related decline in $\mathrm{GH}$ levels is variously interpreted as a symptom of neuroendocrine aging, as one of causes of altered body composition and other unwelcome symptoms of aging, or as a mechanism of natural protection from cancer and other chronic diseases. Absence of $\mathrm{GH}$ signals due to mutations affecting anterior pituitary development, $\mathrm{GH}$ secretion, or $\mathrm{GH}$ receptors produces an impressive extension of longevity in laboratory mice. Extension of healthspan in these animals and analysis of survival curves suggest that in the absence of $\mathrm{GH}$, aging is slowed down or delayed. The corresponding endocrine syndromes in the human have no consistent impact on longevity, but are associated with remarkable protection from age-related disease. Moreover, survival to extremely old age has been associated with reduced somatotropic $(\mathrm{GH}$ and insulin-like growth factor-1) signaling in women and men. In both humans and mice, elevation of GH levels into the supranormal (pathological) range is associated with increased disease risks and reduced life expectancy likely representing acceleration of aging. The widely advertised potential of $\mathrm{GH}$ as an anti-aging agent attracted much interest. However, results obtained thus far have been disappointing with few documented benefits and many troublesome side effects. Possible utility of GH in the treatment of sarcopenia and frailty remains to be explored.
\end{abstract}

Keywords: Aging; Growth hormone; Healthy aging; Life expectancy; Somatotropin

This is an Open Access article distributed under the terms of the Creative Commons Attribution Non-Commercial License (http://creativecommons.org/licenses/by-nc/4.0) which permits unrestricted non-commercial use, distribution, and reproduction in any medium, provided the original work is properly cited.

\section{INTRODUCTION}

Aging is accompanied by numerous changes in the function of the endocrine system. Many of these changes are very pronounced, readily detectable, and thoroughly documented. However, interpretation of the biological meaning of these changes is far from simple. Thus, age-related decline in circulating levels of a particular hormone, dehydroepiandrosterone, estradiol 17 beta, testosterone, or growth hormone (GH) can be viewed as yet another symptom of aging, as one of its potential mechanisms, or as a protective adaptation to alterations in physiological functioning and disease risk in the aging organism. In this article, we will provide an overview of the intricate relationships between GH and aging with emphasis on recent findings.

\section{ACTIVITY OF THE SOMATOTROPIC AXIS DECLINES DURING AGING}

It is well documented that circulating levels of $\mathrm{GH}$ decline with age in various mammalian species, including humans [1-3], domestic dogs [4], and laboratory rodents $[5,6]$. In the human, age-related decrease in

Received: Feb 28, 2018 Revised: Mar 5, 2018 Accepted: Mar 5, 2018 Published online May 11, 2018

Correspondence to: Andrzej Bartke iD https://orcid.org/0000-0002-2569-557X

Department of Internal Medicine, Southern Illinois University School of Medicine, 801 N, Rutledge St., P.O. Box 19628, Springfield, IL 627949628, USA.

Tel: +1-217-545-7655, Fax: +1-217-545-8006, E-mail: abartke@siumed.edu 
plasma GH levels begins soon after attainment of final height and full physical maturation, and continues during the ensuing decades of life [1-3]. Circulating levels of insulin-like growth factor-1 (IGF-1) also decline during human aging, but the decrease is less step than the changes in GH levels, with considerable overlap of values measured in young adults and in elderly subjects [7]. In relating the age-related changes in IGF-1 to the levels of GH, it is necessary to consider that not all of the circulating IGF-1 is derived from GH-dependent hepatic secretion and that peripheral and tissue levels of IGF-1 are differently regulated and thus might exhibit different pattern of changes with age. Moreover, bioavailability of IGF-1 present in the circulation, as well as in the individual organs or tissues, is importantly influenced by complexing with IGF binding proteins (IGFBPs). In mammals, there are at least six IGFBPs. Regulation of biosynthesis of these proteins and their IGF-1 related, as well as IGF-1-independent effects, are outside the scope of this article. The interested reader is referred to recent reviews [8,9]. We will return to the topic of biological actions of IGFBPs in the discussion of the impact of somatotropic axis on longevity of laboratory mice.

\section{EFFECTS OF GROWTH HORMONE THERAPY IN THE ELDERLY}

Consistent with its lipolytic and anabolic activities, administration of GH reduces adiposity and increases lean body mass, including mass of skeletal musculature. A report of such changes in body composition in elderly men with low plasma IGF-1 levels in response to injections of GH published in 1990 [10], attracted enormous attention and wide interest in recombinant human GH as an 'anti-aging' agent. Aging is normally associated with increased adiposity and progressive loss of muscle mass and, thus, effects of GH on body composition were interpreted as reversal of important symptoms of aging. Increases in bone mineral density at some of the examined sites of the skeleton and increased skin thickness in the elderly GH-treated men [10], combined with the evidence for numerous benefits of GH replacement therapy in younger individuals with GH deficiency (GHD) [11-13], helped to increase and sustain interest in GH treatment as an anti-aging intervention.

However, further studies identified various side ef- fects of GH treatment, including joint pain, edema, carpal tunnel syndrome [14,15], and indicated that GHinducted increase in muscle mass is not accompanied by increased strength $[16,17]$. Concerns were also raised that the well documented anti-insulinemic effects of GH and the impact of GH and IGF-1 on the progression and, likely also the incidence, of neoplasms would lead to increased risk of metabolic syndrome, diabetes, and cancer in GH-treated individuals [18,19]. Remarkable reduction in the incidence of cancer and diabetes in individuals with genetic resistance to GH (details later in this article) supports the validity of these concerns. However, commercial promotion of $\mathrm{GH}$ and various GH-related products as anti-aging agents continues and abounds with great and, in some cases, ludicrous promises of 'rejuvenation'. One major complication in critical evaluation of the potential utility of GH as 'anti-aging' therapy is that its proponents usually compare (and often equate) the benefits of injecting $\mathrm{GH}$ in healthy elderly individuals, in which GH levels exhibit a normal age-related decline, to the results obtained in patients diagnosed with adult GHD, that is a pathological and often abrupt decline of GH secretion resulting in levels inappropriately low for age. The benefits of GH therapy in healthy elderly people are controversial and, according to many authors, questionable, unproven, and likely non-existent, with a number of troublesome side effects [14,15]. In contrast, GH therapy can be very beneficial in younger individuals with GHD resulting from traumatic brain injury, treatment of pituitary tumors, or other causes [11-13,20-22]. The benefits include reduced adiposity, increased muscle mass and improvement in glucose homeostasis, general well-being, and some aspects of cognitive function.

Current consensus of medical professional organizations and governmental regulatory agencies is that, while adult GHD is a valid indication for GH replacement therapy, old age without diagnosable somatotropic axis pathology is not [23]. Thus, until further large, well-designed studies are conducted, prescribing GH to endocrinologically-normal middle aged or elderly individuals for the purpose of delaying or reversing aging is generally considered futile, unethical, and, in the United States, also illegal [24]. In this author's opinion, an area which somewhat surprisingly remains understudied, is the potential utility of $\mathrm{GH}$ in the treatment of sarcopenia, one of key components of age-related frailty. Another relatively unexplored area 
is the potential benefits of interventions aimed at increasing the release of endogenous GH. Of particular interest in this regard are agonists of the ghrelin receptor $[25,26]$. However, a major concern in any plans to treat healthy middle-aged or elderly people with $\mathrm{GH}$ or agents stimulating $\mathrm{GH}$ release in an attempt to slow or reverse aging or some of its symptoms is the evidence that GH may have opposite effects. The evidence that physiological actions of GH may promote, rather than prevent, aging will be summarized in the next section of this article. We will also discuss recent studies aimed at identifying mechanisms that appear to be involved.

\section{DOES GROWTH HORMONE ACCELERATE AGING? FINDINGS IN GROWTH HORMONE-DEFICIENT AND GROWTH HORMONE- RESISTANT MICE}

In laboratory mice, disruption of GH signaling leads to a remarkable extension of longevity. This was originally demonstrated in animals homozygous for mutations which disrupt development of selected lineages of secretory cells in the anterior pituitary leading to deficiency of several adenohypophyseal hormones including GH $[27,28]$. These observations were soon extended to animals with isolated GHD due to genetic defects in hypothalamic control of GH release [28,29] and to animals with GH resistance due to targeted disruption of the GH receptor gene [30]. These findings were hard to interpret and were originally received with some skepticism because they implied that normal actions of a hormone have significant 'costs' in terms of longevity, and that a gross defect in the functioning of the endocrine system can have striking benefits for healthy survival. However, the evidence that absence of $\mathrm{GH}$ signaling extends longevity of mice is strong, reproducible, and now generally accepted.

Several aspects of the findings in GH-deficient and GH-resistant mice deserve particular emphasis. First, the significant extension of longevity in these animals is reproducible and not limited to a particular laboratory, diet, or genetic background [31-33]. Second, lifespan is extended in both females and males [27-30]. Third, extension of longevity is associated with a similarly striking extension of healthspan [31,33]. Fourth, the magnitude of the increase in longevity exceeds the effects of most genetic, pharmacological, or dietary interventions that have anti-aging effects in mice. Recent analysis of survival curves of GH-related mouse mutants indicates that their mortality rate is lower than their normal ('wild type') siblings, and increases only late in life, after most of the normal siblings have died [34].

Evidence for extension of the healthspan and for 'healthy aging' of GH-deficient and GH-resistant mice included demonstration that these animals maintain youthful levels of cognitive function into advanced age [35,36]. At the same chronological age, cognitive function of their normal siblings is significantly impaired. Recently, spatial learning and memory were shown to be improved in 12-month-old GH receptor antagonist (GHA) transgenic mice in comparison to their wild type littermates [37]. Since GHA transgenic mice were previously shown to have a normal lifespan [30], these findings indicate that beneficial effects of reduced GH signaling on cognitive function cam be dissociated from extension of longevity and might involve different mechanisms. In support of the negative association of cognitive function and GH signals, pathological excess of GH has been associated with impairments of learning and memory in different lines of transgenic mice [37,38].

A recent study examined longevity of mice lacking both GH and functional GH receptors [39]. While these tiny 'double mutants' were remarkably long-lived compared to their normal siblings, they did not live significantly longer than mice lacking only GH or only GH receptors. In females, survival curves of GH-deficient Ames dwarf, GH-resistant GHRKO, and 'double mutant' $\left(\mathrm{d}^{\mathrm{f}} / \mathrm{KO}\right)$ animals were nearly identical, while longevity of double mutant males was numerically longer than longevity of males from either of the parental strains. Phenotypic characterization of the diminutive $\mathrm{d}^{\mathrm{f}} / \mathrm{KO}$ mice and real-time PCR analysis of gene expression in different tissues revealed multiple differences from wild type animals and from one of the single mutants, but very few characteristics differed from both Ames dwarf and GHRKO mice. These included more extreme increases in relative brain weight and in plasma adiponectin levels [39]. These findings indicate that some of the characteristics of GH-related mutants can be dissociated from longevity. However, it is equally possible that quantitative relationships between longevity and these phenotypic features or levels of messenger RNA for the examined genes exhibit a 'ceiling' or a 'floor' effect with changes greater than those measured in Ames dwarf or GHRKO mice having no 
additional effect on aging and lifespan.

The importance of GH signaling in the control of murine lifespan is further emphasized by the evidence that disruption of signaling events 'downstream' from GH and its receptor also extends longevity. Early findings of extended longevity of female mice heterozygous for the deletion of IGF-1 receptor [40] were confirmed and extended in further studies [41]. A recent report documented extension of lifespan of female mice by inducing IGF-1 deficiency before weaning or during adulthood [42]. Major increase of longevity was seen in mice in which amount of bioavailable IGF-1 was reduced at the tissue level by germline or adult disruption of the gene coding for pregnancy associated plasma protein A, an enzyme degrading IGF-1 binding protein [43,44]. Significant and reproducible extension of longevity was also produced by pharmacological suppression of the activity of mechanistic target of rapamycin a kinase regulated by GH and IGF1 with a major role in RNA translation, protein synthesis, and cell growth [45].
Importantly, conclusions concerning pro-aging effects of normal or elevated GH based on studies in mutant, gene knockout, transgenic, or drug treated mice appear to apply to genetically normal mice and to other mammalian species. Multiple studies reported negative association of adult body size (a strongly GH- and IGF1-dependemt trait) with longevity in comparisons of different mouse strains, selected lines, and individual animals [46-48]. Similar associations were documented in rats [49], domestic dogs [50,51], and horses [52]. Human studies addressing this issue with be discussed later in the article.

\section{MECHANISMS OF EXTENDED LONGEVITY OF ANIMALS WITH GROWTH HORMONE-RELATED MUTATIONS}

The demonstration of a remarkable extension of longevity in GH-deficient and GH-resistant mice prompted a search for mechanisms linking GH signaling with

Table 1. Mechanisms of extended healthspan and longevity in GH-deficient and GH-resistant mice (details and references in the text)

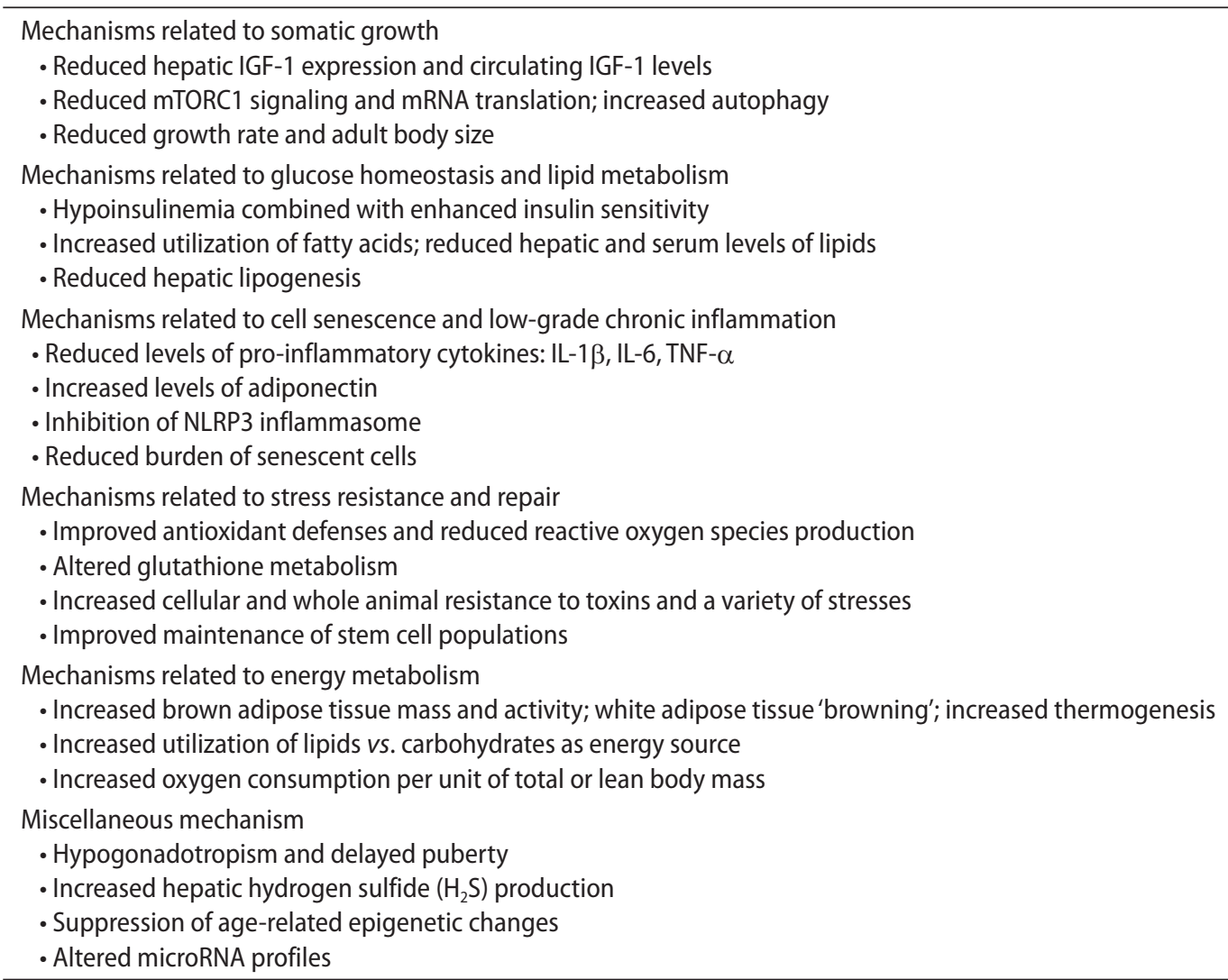

GH: growth hormone, IGF-1: insulin-like growth factor-1, mTORC1: mechanistic target of rapamycin complex 1, IL: interleukin, TNF- $\alpha$ : tumor necrosis factor- $\alpha$. 
the rate of aging. Detailed characterization of the phenotypic characteristics of these long-lived GH-related mutants [31-33] together with analysis of their profiles of gene expression [53-55] and their responses to dietary, hormonal, surgical, or pharmacological interventions [29,56-60] led to the identification of multiple candidate mechanisms of the extension of healthspan and lifespan in these animals (Table 1). The picture that emerges from these studies suggests interplay of multiple interacting mechanisms that translate severe reduction (or absence) of GH signals into a healthy 'longevous' phenotype resembling, but not identical to, the phenotype of animals subjected to chronic calorie restriction. Some of the interactions between various mechanisms of delayed and/or slower aging in GHdeficient and GH-resistant mice are shown in Fig. 1.

Interpretation of the findings that identify likely mechanisms of slower or delayed aging is complicated because mechanisms can be very difficult to separate from the symptoms ('biomarkers') or consequences of aging, and firm evidence of causality is difficult to obtain. However, GH-deficient and GH-resistant mice are uniquely suitable for identifying mechanistic links between GH and longevity and, more broadly, for studies of the mechanisms of mammalian aging. Because their propensity for extreme longevity is inherited as fully recessive trait and heterozygous carriers of these mutations as well as homozygous males are fertile, it is a standard practice to use a breeding scheme in which mutant and normal offspring are born in the same litter. This makes it possible to compare animals that shared the same uterine environment, maternal care and provision of nutrients, as well as every detail of laboratory environment, and genetic background, and differ only by the presence or absence of two copies of the loss-of-function mutation at a particular chromosomal site. Moreover, since their extended longevity is genetically determined, it is possible to study these mutants as well as the matched control (wild type) animals when they are young and their physiological characteristics are not impacted by the process of aging and only minimally (or not at all) impacted by the differences in life expectancy [61].

Our laboratory is particularly interested in the role of reduced chronic low-grade inflammation in adipose tissue [62,63] and in the central nervous system [64], the combination of reduced insulin levels and enhanced insulin sensitivity [65], and the alterations in thermogenesis and energy metabolism [66] as mechanisms linking reduced GH signaling with extensions of healthspan and lifespan. We are also pursuing the question of possible differences in the role of $\mathrm{GH}$ at different stages of the life history in the control of aging. The evidence available to date indicates that $\mathrm{GH}$ actions during the rapid peri-pubertal growth may have major impact on longevity [67], but GH signaling during adult life also plays a role [68]. We will return to this issue in the last (closing) section of this article.

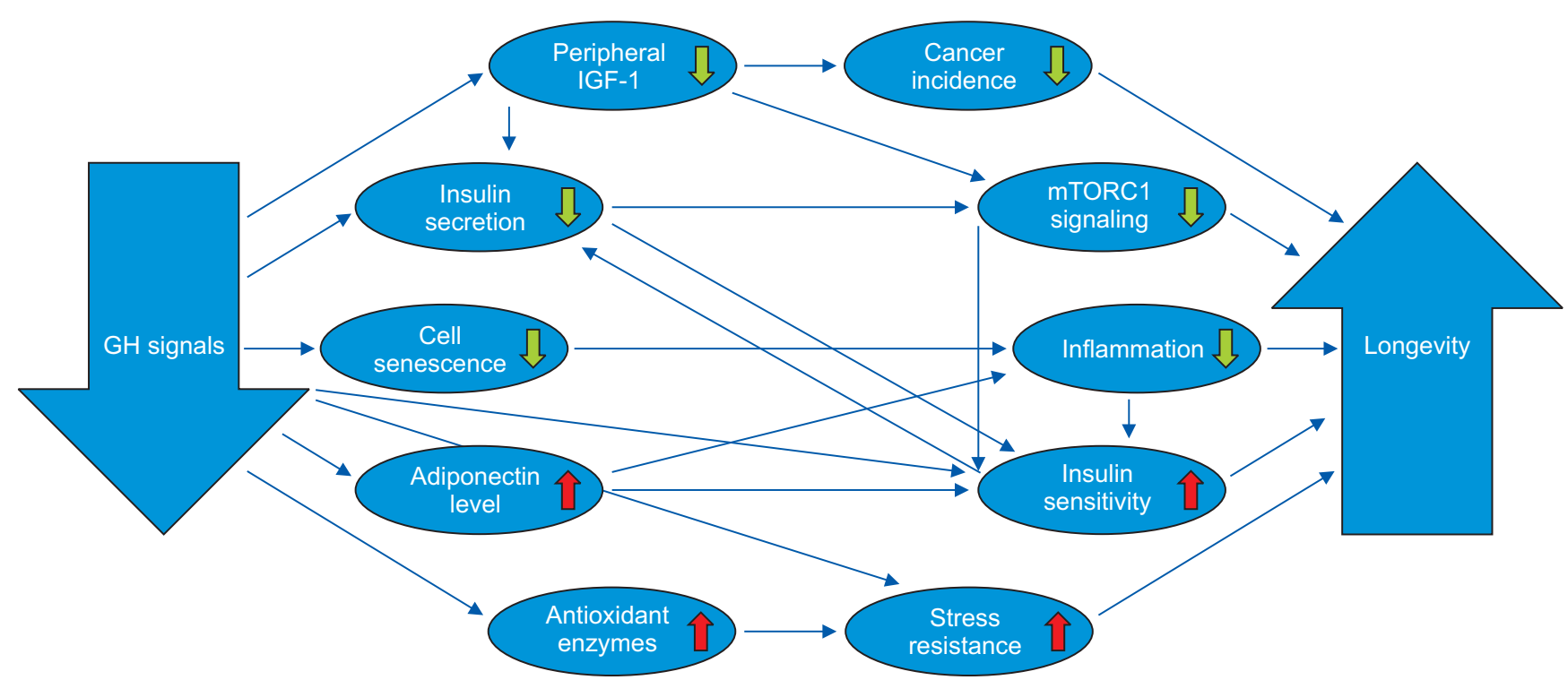

Fig. 1. Key mechanisms mediating the effects of reduced growth hormone (GH) signaling on aging and longevity ( $\downarrow$ decrease, $\uparrow$ increase). IGF-1: insulin-like growth factor-1, mTORC1: mechanistic target of rapamycin complex 1. 


\section{GROWTH HORMONE AND HUMAN LONGEVITY}

The initial evidence for a role of GH signaling in the control of human aging was largely indirect and often considered controversial. Samaras [69] reported numerous examples of a negative correlation of longevity with height, a GH-dependent trait. However, some examples of taller people living longer were also reported [70]. Subsequent studies provided new examples of longer survival of shorter people [71] and uncovered association of polymorphism of genes coding for GH, IGF1, IGF-1 receptor and their downstream targets, with exceptional longevity [33,71-74].

Reports of remarkably extended longevity in diminutive mice lacking GH or GHR increased interest in aging of humans with the same genetic defects or with dwarfism of different etiologies but few clear answers emerged from these studies. Although some individuals with isolated GHD resulting from mutations affecting GH releasing hormone, genetic hypopituitarism (including GHD) resulting from Prop1 loss of function mutations, or with GH resistance (the Laron syndrome) attained very old age, average longevity did not appear to be altered by these mutations [75-78]. In one study, isolated GHD was associated with markedly reduced longevity [79]. Intriguingly, reduced longevity also characterizes patients with pathologically increased GH levels in the syndrome of acromegaly $[80,81]$. The rare syndrome of gigantism with excessive GH secretion starting before maturation appears to be associated with very high risk of early mortality, although the evidence consists primarily from case studies $[82,83]$ and media reports. Increased risk of diabetes, cardiovascular disease and cancer associated with acromegaly resembles the effects of chronological age on the incidence of these disease and, thus, could perhaps be interpreted as an indication of accelerated aging. Transgenic mice with a massive increase in circulating GH levels due to ectopic expression of heterologous GH genes exhibit a significant, often dramatic, reduction of longevity along with multiple symptoms of accelerated aging [84].

Research conducted during the last decade provided a considerable amount of new evidence for the role of GH in human aging. Study of a large cohort of American men of Japanese ancestry confirmed earlier reports of negative association of height (a GH-related trait) and longevity, and indicated that this association was most pronounced in the eighth and ninth decades of life [71]. Importantly, this study also demonstrated that height is negatively associated with the FOXO3 longevity allele and positively associated with fasting blood insulin levels, both of which have been mechanistically related to the process of aging in humans and other species. Detailed analysis of pulsatile pattern of GH relates in serum samples collected every 10 minutes for 24 hours, revealed that offspring of longlived families which are themselves genetically predisposed to increased longevity secrete less GH than their spouses or partners [85]. Moreover, $\mathrm{GH}$ secretion in these individuals was more tightly controlled [85].

In a different cohort of long-lived people, Milman et al [86] demonstrated negative association of circulating IGF-1 levels and survival in nonagenarian women. Ben-Avraham et al [87] recently reported increased longevity of men homozygous for a mutation of GH receptor. Reduced serum levels of IGF-1 in these individuals were consistent with reduced GH signaling but, unexpectedly, they were taller than men without this mutation. Tanisawa et al [88] approached the relationship between growth and longevity by comparing the frequency of height increasing alleles in large cohorts of centenarians and control subjects. This interesting approach removes some important confounders, such as nutrition and childhood diseases, that can influence adult height. The results revealed inverse association between height-increasing alleles and extreme longevity in Japanese women [88].

There is also considerable evidence that mutations which disrupt GH signaling in humans offer significant protection from various age-associated diseases. Early observations of reduced cancer risk in individuals with Laron dwarf syndrome (genetic GH resistance) [89] were followed by demonstration that members of a large cohort of Laron dwarfs in Ecuador are almost completely protected from cancer and diabetes [78]. More recently, these individuals were also shown to have increased adiponectin levels and enhanced insulin sensitivity in spite of greater percentage of body fat [90], enhanced cognitive performance and structural features of the brain hippocampus and other brain regions resembling younger unaffected relatives [91] Aguiar-Oliveira et al [77] reported that individuals with isolated GHD in Brazil are remarkably protected from atherosclerosis in spite of unfavorable serum 
lipid profiles and frequent obesity, that they tend to 'age well', in terms of physical appearance and fitness and can survive to an advanced age with one becoming a centenarian (Aguiar-Oliveira, personal communication).

Discrepancies between the findings in different cohorts of individuals with genetic defects in GH signaling are difficult to explain. Rarity of these genetic syndromes precludes recruitment of large cohorts needed for critical analysis of mortality rates, median, and maximal longevity. The impact of genomic, lifestyle, and medical care differences between the ethnically diverse and geographically distant populations examined in these studies could, of course, be suspected, but explanations based on these differences would, at this point, be entirely speculative. It is also unclear why the protection from cancer, diabetes, and atherosclerosis in the affected individuals is not associated with a clear increase in life expectancy. A relatively high incidence of alcoholism and accidental deaths among the GHresistant individuals in Ecuador [78] may provide at least a partial explanation. It also hints at a possible interaction of this syndrome with social, behavioral, and environmental factors, an issue that would seem to merit further studies.

\section{CONCLUSION: OVERVIEW; WHAT DO WE KNOW AND WHAT ARE THE KEY UNANSWERED QUESTIONS?}

The impact of GH actions on longevity of laboratory mice is major, consistent and well documented, and some of the findings obtained in these animals clearly apply to other mammalian species, including humans. Still, inconsistencies and controversies abound. Prominent among them is the issue of differences between findings concerning longevity in mice and humans. However, pathological GH excess is associated with comorbidities and reduced longevity in both species. Negative association of GH levels and adult body size (a GH-dependent trait) with longevity was reported in multiple studies in both species, but these relationships are much more pronounced and consistent in mice. What could be the reasons? The most obvious differences are that human growth and adult height are influenced by nutrition, childhood disease, and access to healthcare (all related to the birth cohort and socioeconomic status), and human longevity is impacted by smoking, dietary and exercise habits, alcohol and drug use, traffic and industrial accidents, murder, and suicide, while none of these factors can impact the results of experimental studies of aging in mice. Another important difference that we are currently evaluating is, perhaps surprisingly, the difference in environmental (ambient) temperature. Laboratory mice are routinely housed at room temperature and it is easy for us to forget that this represents a comfortable indoor temperature for humans wearing light clothing and it is much below the thermoneutral and the preferred temperature for mice, which is approximately $30^{\circ} \mathrm{C}\left(86^{\circ} \mathrm{F}\right)$ [92]. We have shown that major metabolic differences, as well as differences in gene expression profiles, between normal (wild type) mice and long-lived mice with diminished GH signaling disappear or are greatly reduced when the mice are housed in a thermoneutral environment [93, unpublished data]. Thus, we should probably not expect full consistency between findings obtained in humans living in an environment close to thermoneutrality and in mice exposed to a constant cold stress $[94,95]$.

In trying to reconcile some seemingly inconsistent findings concerning $\mathrm{GH}$ and aging in different species, it may also be necessary to consider that the question, 'does GH promote or prevent aging?' is overly simplistic. Emerging evidence suggests that the impact of GH on aging is not the same at different stages of life history. For example, interesting studies conducted in the Sonntag laboratory in dwarf rats suggests that GH signals have a positive effect on longevity during development, but a negative impact later on, most likely by increasing the risk of cancer [96]. However, results of GH replacement therapy in juvenile GH-deficient mice suggest that the absence of $\mathrm{GH}$ signals during development importantly contributes to the remarkable extended longevity of these mutants [67]. The mechanisms by which early-life changes in GH signals influence adult phenotype, aging, and longevity are almost certainly epigenetic. This intriguing possibility is indirectly supported by the recently reported impact of Ames dwarfism on the epigenetic signatures of aging [97,98], and clearly deserves further study. However, the lifespan of the dwarf mice was not completely normalized ('rescued') by early-life GH therapy, suggesting that adult GH levels are also involved in the control of aging. A recent report that disrupting GHR gene in adult female mice extends their longevity [68] provides direct evidence for the role of $\mathrm{GH}$ signaling during 
adult life in the control of mammalian aging.

It is also interesting to consider that the evidence for delayed puberty, reduced fecundity, and extended lifespan of GH-deficient and GH-resistant mice fits perfectly into the concept of antagonistic pleiotropy proposed many years ago [99]. Genes related to the somatotropic signaling promote growth, sexual maturation, and fecundity, the key elements of evolutionary fitness and, thus, their actions would have been selected for in the course of evolution, even though later in life they may have detrimental effects on disease risk and survival. This concept likely applies broadly to the genetic control of aging and fits remarkably well with the rather counterintuitive findings that most of the strong 'longevity genes' discovered in various organisms are either loss-of-function mutations or mutations that reduce the level of gene expression. Much work will be needed to identify the role of somatotropic signaling at different stages of life history in the control of aging, risks of age-related disease and longevity. We believe that studies of the role of GH in aging in different species, the mechanisms involved, and the interactions of these mechanisms with environmental factors will lead to new insights with significant implications for both individual and public health.

\section{ACKNOWLEDGEMENTS}

Writing of this article and our recent and current studies of this topic were supported by NIA (NIH) via grants R01AG019899 and R21AG051869. We apologize to those whose work pertinent to the issues discussed was not cited due to limitations of the format or to inadvertent omissions.

\section{Disclosure}

The author has no potential conflicts of interest to disclose.

\section{Author Contribution}

Article conception \& design: Bartke A. Data acquisition: Bartke A. Data analysis and interpretation: Bartke A. Writing of the manuscript: Bartke A. Receiving grant: Bartke A. Approval of final manuscript: Bartke A.

\section{REFERENCES}

1. Corpas E, Harman SM, Blackman MR. Human growth hormone and human aging. Endocr Rev 1993;14:20-39.

2. Veldhuis JD. Aging and hormones of the hypothalamo-pituitary axis: gonadotropic axis in men and somatotropic axes in men and women. Ageing Res Rev 2008;7:189-208.

3. Bartke A, Westendorp RGJ, van Heemst D. Endocrine systems. In: Vigj J, Campisi J, Lithgow GJ, editors. Molecular and cellular biology of aging. Washington, D.C.: Gerontological Society of America; 2015;250-74.

4. Müller EE, Cella SG, De Gennaro Colonna V, Parenti M, Cocchi D, Locatelli V. Aspects of the neuroendocrine control of growth hormone secretion in ageing mammals. J Reprod Fertil Suppl 1993;46:99-114.

5. Sonntag WE, Steger RW, Forman LJ, Meites J. Decreased pulsatile release of growth hormone in old male rats. Endocrinology 1980;107:1875-9.

6. Kuwahara S, Kesuma Sari D, Tsukamoto Y, Tanaka S, Sasaki F. Age-related changes in growth hormone $(\mathrm{GH})$-releasing hormone and somatostatin neurons in the hypothalamus and in GH cells in the anterior pituitary of female mice. Brain Res 2004;1025:113-22.

7. Maggio M, Ble A, Ceda GP, Metter EJ. Decline in insulin-like growth factor-I levels across adult life span in two large population studies. J Gerontol A Biol Sci Med Sci 2006;61:182-3.

8. Baxter RC. IGF binding proteins in cancer: mechanistic and clinical insights. Nat Rev Cancer 2014;14:329-41.

9. Clemmons DR. Modifying IGF1 activity: an approach to treat endocrine disorders, atherosclerosis and cancer. Nat Rev Drug Discov 2007;6:821-33.

10. Rudman D, Feller AG, Nagraj HS, Gergans GA, Lalitha PY, Goldberg AF, et al. Effects of human growth hormone in men over 60 years old. N Engl J Med 1990;323:1-6.

11. Rosén T, Johannsson G, Johansson JO, Bengtsson BA. Consequences of growth hormone deficiency in adults and the benefits and risks of recombinant human growth hormone treatment. A review paper. Horm Res 1995;43:93-9.

12. Salomon F, Cuneo RC, Hesp R, Sönksen PH. The effects of treatment with recombinant human growth hormone on body composition and metabolism in adults with growth hormone deficiency. N Engl J Med 1989;321:1797-803.

13. Rosenfalck AM, Maghsoudi S, Fisker S, Jørgensen JO, Christiansen JS, Hilsted J, et al. The effect of 30 months of lowdose replacement therapy with recombinant human growth hormone (rhGH) on insulin and C-peptide kinetics, insulin secretion, insulin sensitivity, glucose effectiveness, and body composition in GH-deficient adults. J Clin Endocrinol Metab 
$2000 ; 85: 4173-81$

14. Blackman MR, Sorkin JD, Münzer T, Bellantoni MF, BusbyWhitehead J, Stevens TE, et al. Growth hormone and sex steroid administration in healthy aged women and men: a randomized controlled trial. JAMA 2002;288:2282-92.

15. Liu H, Bravata DM, Olkin I, Nayak S, Roberts B, Garber AM, et al. Systematic review: the safety and efficacy of growth hormone in the healthy elderly. Ann Intern Med 2007;146:104-15.

16. Lange $\mathrm{KH}$, Andersen JL, Beyer N, Isaksson F, Larsson B, Rasmussen $\mathrm{MH}$, et al. $\mathrm{GH}$ administration changes myosin heavy chain isoforms in skeletal muscle but does not augment muscle strength or hypertrophy, either alone or combined with resistance exercise training in healthy elderly men. J Clin Endocrinol Metab 2002;87:513-23.

17. Taaffe DR, Pruitt L, Reim J, Hintz RL, Butterfield G, Hoffman $\mathrm{AR}$, et al. Effect of recombinant human growth hormone on the muscle strength response to resistance exercise in elderly men. J Clin Endocrinol Metab 1994;79:1361-6.

18. Swerdlow AJ, Cooke R, Beckers D, Borgström B, Butler G, Carel JC, et al. Cancer risks in patients treated with growth hormone in childhood: The SAGhE European Cohort Study. J Clin Endocrinol Metab 2017;102:1661-72.

19. Boguszewski CL, Boguszewski MC, Kopchick JJ. Growth hormone, insulin-like growth factor system and carcinogenesis. Endokrynol Pol 2016;67:414-26.

20. Capalbo D, Barbieri F, Improda N, Giallauria F, Di Pietro E, Rapacciuolo A, et al. Growth hormone improves cardiopulmonary capacity and body composition in children with growth hormone deficiency. J Clin Endocrinol Metab 2017;102:4080-8

21. Sathiavageeswaran M, Burman P, Lawrence D, Harris AG, Falleti MG, Maruff P, et al. Effects of GH on cognitive function in elderly patients with adult-onset GH deficiency: a placebo-controlled 12-month study. Eur J Endocrinol 2007;156:439-47.

22. Moreau OK, Cortet-Rudelli C, Yollin E, Merlen E, Daveluy W, Rousseaux M. Growth hormone replacement therapy in patients with traumatic brain injury. J Neurotrauma 2013;30:998-1006.

23. Sattler FR. Growth hormone in the aging male. Best Pract Res Clin Endocrinol Metab 2013;27:541-55.

24. Perls TT, Reisman NR, Olshansky SJ. Provision or distribution of growth hormone for "antiaging": clinical and legal issues. JAMA 2005;294:2086-90.

25. Nass R, Park J, Thorner MO. Growth hormone supplementation in the elderly. Endocrinol Metab Clin North Am 2007;36:233-45.

26. Friedman SD, Baker LD, Borson S, Jensen JE, Barsness SM,
Craft S, et al. Growth hormone-releasing hormone effects on brain $\gamma$-aminobutyric acid levels in mild cognitive impairment and healthy aging. JAMA Neurol 2013;70:883-90.

27. Brown-Borg HM, Borg KE, Meliska CJ, Bartke A. Dwarf mice and the ageing process. Nature 1996;384:33.

28. Flurkey K, Papaconstantinou J, Miller RA, Harrison DE. Lifespan extension and delayed immune and collagen aging in mutant mice with defects in growth hormone production. Proc Natl Acad Sci U S A 2001;98:6736-41.

29. Sun LY, Spong A, Swindell WR, Fang Y, Hill C, Huber JA, et al. Growth hormone-releasing hormone disruption extends lifespan and regulates response to caloric restriction in mice. Elife 2013;2:e01098.

30. Coschigano KT, Holland AN, Riders ME, List EO, Flyvbjerg A, Kopchick JJ. Deletion, but not antagonism, of the mouse growth hormone receptor results in severely decreased body weights, insulin, and insulin-like growth factor I levels and increased life span. Endocrinology 2003;144:3799-810.

31. Bartke A. Single-gene mutations and healthy ageing in mammals. Philos Trans R Soc Lond B Biol Sci 2011;366:28-34.

32. Brown-Borg HM. The somatotropic axis and longevity in mice. Am J Physiol Endocrinol Metab 2015;309:E503-10.

33. Bartke A, Sun LY, Longo V. Somatotropic signaling: trade-offs between growth, reproductive development, and longevity. Physiol Rev 2013;93:571-98.

34. Koopman JJ, van Heemst D, van Bodegom D, Bonkowski MS, Sun LY, Bartke A. Measuring aging rates of mice subjected to caloric restriction and genetic disruption of growth hormone signaling. Aging (Albany NY) 2016;8:539-46.

35. Kinney BA, Meliska CJ, Steger RW, Bartke A. Evidence that Ames dwarf mice age differently from their normal siblings in behavioral and learning and memory parameters. Horm Behav 2001;39:277-84.

36. Kinney BA, Coschigano KT, Kopchick JJ, Steger RW, Bartke A. Evidence that age-induced decline in memory retention is delayed in growth hormone resistant GH-R-KO (Laron) mice. Physiol Behav 2001;72:653-60.

37. Basu A, McFarlane HG, Kopchick JJ. Spatial learning and memory in male mice with altered growth hormone action. Horm Behav 2017;93:18-30.

38. Rollo CD, Ko CV, Tyerman JGA, Kajiura LJ. The growth hormone axis and cognition: empirical results and integrated theory derived from giant transgenic mice. Can J Zool 1999;77:1874-90.

39. Gesing A, Wiesenborn D, Do A, Menon V, Schneider A, Victoria $\mathrm{B}$, et al. A long-lived mouse lacking both growth hormone and growth hormone receptor: a new animal model for aging studies. J Gerontol A Biol Sci Med Sci 2017;72:1054-61. 
40. Holzenberger M, Dupont J, Ducos B, Leneuve P, Géloën A, Even PC, et al. IGF-1 receptor regulates lifespan and resistance to oxidative stress in mice. Nature 2003;421:182-7.

41. Xu J, Gontier G, Chaker Z, Lacube P, Dupont J, Holzenberger M. Longevity effect of IGF-1R(+/-) mutation depends on genetic background-specific receptor activation. Aging Cell 2014;13:19-28.

42. Ashpole NM, Logan S, Yabluchanskiy A, Mitschelen MC, Yan H, Farley JA, et al. IGF-1 has sexually dimorphic, pleiotropic, and time-dependent effects on healthspan, pathology, and lifespan. Geroscience 2017;39:129-45.

43. Conover CA, Bale LK. Loss of pregnancy-associated plasma protein A extends lifespan in mice. Aging Cell 2007;6:727-9.

44. Bale LK, West SA, Conover CA. Inducible knockdown of pregnancy-associated plasma protein-A gene expression in adult female mice extends life span. Aging Cell 2017;16:895-7.

45. Harrison DE, Strong R, Sharp ZD, Nelson JF, Astle CM, Flurkey K, et al. Rapamycin fed late in life extends lifespan in genetically heterogeneous mice. Nature 2009;460:392-5.

46. Miller RA, Harper JM, Galecki A, Burke DT. Big mice die young: early life body weight predicts longevity in genetically heterogeneous mice. Aging Cell 2002;1:22-9.

47. Yuan R, Tsaih SW, Petkova SB, Marin de Evsikova C, Xing S, Marion MA, et al. Aging in inbred strains of mice: study design and interim report on median lifespans and circulating IGF1 levels. Aging Cell 2009;8:277-87.

48. Eklund J, Bradford GE. Longeveity and lifetime body weight in mice selected for rapid growth. Nature 1977;265:48-9.

49. Rollo CD. Growth negatively impacts the life span of mammals. Evol Dev 2002;4:55-61.

50. Greer KA, Hughes LM, Masternak MM. Connecting serum IGF-1, body size, and age in the domestic dog. Age (Dordr) 2011;33:475-83.

51. Patronek GJ, Waters DJ, Glickman LT. Comparative longevity of pet dogs and humans: implications for gerontology research. J Gerontol A Biol Sci Med Sci 1997;52:B171-8.

52. Brosnahan MM, Paradis MR. Demographic and clinical characteristics of geriatric horses: 467 cases (1989-1999). J Am Vet Med Assoc 2003;223:93-8.

53. Tsuchiya T, Dhahbi JM, Cui X, Mote PL, Bartke A, Spindler SR. Additive regulation of hepatic gene expression by dwarfism and caloric restriction. Physiol Genomics 2004;17:307-15.

54. Dhahbi J, Li X, Tran T, Masternak MM, Bartke A. Circulating blood leukocyte gene expression profiles: effects of the Ames dwarf mutation on pathways related to immunity and inflammation. Exp Gerontol 2007;42:772-88.

55. Stout MB, Swindell WR, Zhi X, Rohde K, List EO, Berryman $\mathrm{DE}$, et al. Transcriptome profiling reveals divergent expres- sion shifts in brown and white adipose tissue from long-lived GHRKO mice. Oncotarget 2015;6:26702-15.

56. Bartke A, Wright JC, Mattison JA, Ingram DK, Miller RA, Roth GS. Extending the lifespan of long-lived mice. Nature 2001;414:412.

57. Bonkowski MS, Rocha JS, Masternak MM, Al Regaiey KA, Bartke A. Targeted disruption of growth hormone receptor interferes with the beneficial actions of calorie restriction. Proc Natl Acad Sci U S A 2006;103:7901-5.

58. Masternak MM, Bartke A, Wang F, Spong A, Gesing A, Fang $\mathrm{Y}$, et al. Metabolic effects of intra-abdominal fat in GHRKO mice. Aging Cell 2012;11:73-81.

59. Darcy J, McFadden S, Fang Y, Huber JA, Zhang C, Sun LY, et al. Brown adipose tissue function is enhanced in long-lived, male ames dwarf mice. Endocrinology 2016;157:4744-53.

60. Fang Y, Hill CM, Darcy J, Reyes-Ordoñez A, Arauz E, McFadden $S$, et al. Effects of rapamycin on growth hormone receptor knockout mice. Proc Natl Acad Sci U S A 2018;115:E1495-03.

61. Panici JA, Wang F, Bonkowski MS, Spong A, Bartke A, Pawlikowska $\mathrm{L}$, et al. Is altered expression of hepatic insulinrelated genes in growth hormone receptor knockout mice due to GH resistance or a difference in biological life spans? J Gerontol A Biol Sci Med Sci 2009;64:1126-33.

62. Wang Z, Al-Regaiey KA, Masternak MM, Bartke A. Adipocytokines and lipid levels in Ames dwarf and calorie-restricted mice. J Gerontol A Biol Sci Med Sci 2006;61:323-31.

63. Spadaro O, Goldberg EL, Camell CD, Youm YH, Kopchick JJ, Nguyen KY, et al. Growth hormone receptor deficiency protects against age-related NLRP3 inflammasome activation and immune senescence. Cell Rep 2016;14:1571-80.

64. Hascup ER, Wang F, Kopchick JJ, Bartke A. Inflammatory and glutamatergic homeostasis are involved in successful aging. J Gerontol A Biol Sci Med Sci 2016;71:281-9.

65. Bonkowski MS, Dominici FP, Arum O, Rocha JS, Al Regaiey KA, Westbrook R, et al. Disruption of growth hormone receptor prevents calorie restriction from improving insulin action and longevity. PLoS One 2009;4:e4567.

66. Westbrook R, Bonkowski MS, Strader AD, Bartke A. Alterations in oxygen consumption, respiratory quotient, and heat production in long-lived GHRKO and Ames dwarf mice, and short-lived bGH transgenic mice. J Gerontol A Biol Sci Med Sci 2009;64:443-51.

67. Sun LY, Fang Y, Patki A, Koopman JJ, Allison DB, Hill CM, et al. Longevity is impacted by growth hormone action during early postnatal period. Elife 2017;6:e24059. doi: 10.7554/ eLife.24059.

68. Junnila RK, Duran-Ortiz S, Suer O, Sustarsic EG, Berryman $\mathrm{DE}$, List EO, et al. Disruption of the GH receptor gene in 
adult mice increases maximal lifespan in females. Endocrinology 2016;157:4502-13

69. Samaras TT. Human body size and the laws of scaling: physiological, performance, growth, longevity and ecological ramifications. New York: Nova Science Publishers, Inc.; 2007.

70. Perkins JM, Subramanian SV, Davey Smith G, Özaltin E. Adult height, nutrition, and population health. Nutr Rev 2016;74:149-65.

71. He Q, Morris BJ, Grove JS, Petrovitch H, Ross W, Masaki $\mathrm{KH}$, et al. Shorter men live longer: association of height with longevity and FOXO3 genotype in American men of Japanese ancestry. PLoS One 2014;9:e94385.

72. Bonafè M, Barbieri M, Marchegiani F, Olivieri F, Ragno E, Giampieri C, et al. Polymorphic variants of insulin-like growth factor I (IGF-I) receptor and phosphoinositide 3-kinase genes affect IGF-I plasma levels and human longevity: cues for an evolutionarily conserved mechanism of life span control. J Clin Endocrinol Metab 2003;88:3299-304.

73. van Heemst D, Beekman M, Mooijaart SP, Heijmans BT, Brandt BW, Zwaan BJ, et al. Reduced insulin/IGF-1 signalling and human longevity. Aging Cell 2005;4:79-85.

74. Suh Y, Atzmon G, Cho MO, Hwang D, Liu B, Leahy DJ, et al. Functionally significant insulin-like growth factor I receptor mutations in centenarians. Proc Natl Acad Sci U S A 2008;105:3438-42.

75. Krzisnik C, Kolacio Z, Battelino T, Brown M, Parks JS, Laron Z. The "little people" of the island of Krk - revisited. Etiology of hypopituitarism revealed. J Endocr Genet 1999;1:9-19.

76. Laron Z, Kauli R, Lapkina L, Werner H. IGF-I deficiency, longevity and cancer protection of patients with Laron syndrome. Mutat Res Rev Mutat Res 2017;772:123-33.

77. Aguiar-Oliveira MH, Souza AHO, Oliveira CRP, Campos VC, Oliveira-Neto LA, Salvatori R. The multiple facets of GHRH/ GH/IGF-I axis: lessons from lifetime, untreated, isolated GH deficiency due to a GHRH receptor gene mutation. Eur J Endocrinol 2017;177:R85-97.

78. Guevara-Aguirre J, Balasubramanian P, Guevara-Aguirre M, Wei M, Madia F, Cheng CW, et al. Growth hormone receptor deficiency is associated with a major reduction in pro-aging signaling, cancer, and diabetes in humans. Sci Transl Med 2011;3:70ra13.

79. Besson A, Salemi S, Gallati S, Jenal A, Horn R, Mullis PS, et al. Reduced longevity in untreated patients with isolated growth hormone deficiency. J Clin Endocrinol Metab 2003;88:3664-7.

80. Jadresic A, Banks LM, Child DF, Diamant L, Doyle FH, Fraser TR, et al. The acromegaly syndrome. Relation between clinical features, growth hormone values and radiological characteristics of the pituitary tumours. Q J Med 1982;51:189-204.
81. Orme SM, McNally RJ, Cartwright RA, Belchetz PE. Mortality and cancer incidence in acromegaly: a retrospective cohort study. United Kingdom Acromegaly Study Group. J Clin Endocrinol Metab 1998;83:2730-4.

82. Chahal HS, Stals K, Unterländer M, Balding DJ, Thomas MG, Kumar AV, et al. AIP mutation in pituitary adenomas in the 18th century and today. N Engl J Med 2011;364:43-50.

83. Ramírez-Rentería C, Hernández-Ramírez LC, PortocarreroOrtiz L, Vargas G, Melgar V, Espinosa E, et al. AIP mutations in young patients with acromegaly and the Tampico Giant: the Mexican experience. Endocrine 2016;53:402-11.

84. Bartke A. Can growth hormone $(\mathrm{GH})$ accelerate aging? Evidence from GH-transgenic mice. Neuroendocrinology 2003;78:210-6.

85. van der Spoel E, Jansen SW, Akintola AA, Ballieux BE, Cobbaert CM, Slagboom PE, et al. Growth hormone secretion is diminished and tightly controlled in humans enriched for familial longevity. Aging Cell 2016. doi: 10.1111/acel.12519.

86. Milman S, Atzmon G, Huffman DM, Wan J, Crandall JP, Cohen $\mathrm{P}$, et al. Low insulin-like growth factor-1 level predicts survival in humans with exceptional longevity. Aging Cell 2014;13:769-71.

87. Ben-Avraham D, Govindaraju DR, Budagov T, Fradin D, Durda P, Liu B, et al. The GH receptor exon 3 deletion is a marker of male-specific exceptional longevity associated with increased GH sensitivity and taller stature. Sci Adv 2017;3:e1602025.

88. Tanisawa K, Hirose N, Arai Y, Shimokata H, Yamada Y, Kawai $\mathrm{H}$, et al. Inverse association between height-increasing alleles and extreme longevity in Japanese women. J Gerontol A Biol Sci Med Sci 2017. doi: 10.1093/gerona/glx155.

89. Laron Z. The GH-IGF1 axis and longevity. The paradigm of IGF1 deficiency. Hormones (Athens) 2008;7:24-7.

90. Guevara-Aguirre J, Rosenbloom AL, Balasubramanian P, Teran E, Guevara-Aguirre M, Guevara C, et al. GH Receptor deficiency in ecuadorian adults is associated with obesity and enhanced insulin sensitivity. J Clin Endocrinol Metab 2015;100:2589-96.

91. Nashiro K, Guevara-Aguirre J, Braskie MN, Hafzalla GW, Velasco R, Balasubramanian P, et al. Brain structure and function associated with younger adults in growth hormone receptor-deficient humans. J Neurosci 2017;37:1696-707.

92. Gordon CJ. Thermal physiology of laboratory mice: defining thermoneutrality. J Therm Biol 2012;37:654-85.

93. Westbrook R. The effects of altered growth hormone signaling on murine metabolism. Carbondale (IL): Southern Illinois University; 2012.

94. Karp CL. Unstressing intemperate models: how cold stress 
undermines mouse modeling. J Exp Med 2012;209:1069-74.

95. Maloney SK, Fuller A, Mitchell D, Gordon C, Overton JM. Translating animal model research: does it matter that our rodents are cold? Physiology (Bethesda) 2014;29:413-20.

96. Sonntag WE, Carter CS, Ikeno Y, Ekenstedt K, Carlson CS, Loeser RF, et al. Adult-onset growth hormone and insulinlike growth factor I deficiency reduces neoplastic disease, modifies age-related pathology, and increases life span. Endocrinology 2005;146:2920-32.

97. Wang T, Tsui B, Kreisberg JF, Robertson NA, Gross AM,
Yu MK, et al. Epigenetic aging signatures in mice livers are slowed by dwarfism, calorie restriction and rapamycin treatment. Genome Biol 2017;18:57.

98. Cole JJ, Robertson NA, Rather MI, Thomson JP, McBryan T, Sproul D, et al. Diverse interventions that extend mouse lifespan suppress shared age-associated epigenetic changes at critical gene regulatory regions. Genome Biol 2017;18:58.

99. Williams GC. Pleiotropy, natural selection, and the evolution of senescence. Evolution 1957;11:398-411. 